\title{
A Nanodrop Spectrophotometric Method and Stability Indicating for Determination of Amlodipine Besylate in Pharmaceutical Formulations of Kurdistan of Iraq
}

\author{
Faroq Omer Qasim $^{\mathrm{a}, *}$, Nidhal Meena Sher Mohammed ${ }^{\mathrm{b}}$ \\ ${ }^{a}$ Department of Horticulture, Akre technical college, DPU, Kurdistan Region, Iraq- (faroq.omer@dpu.edu.krd) \\ ${ }^{\mathrm{b}}$ Department of Chemistry, Faculty of Science, University of Zakho,Kurdistan Region, Iraq-(nidhal.mohammed@uoz.edu.krd)
}

Received: Dec., 2020 / Accepted: Jan., 2021 / Published: Mar.,2021 https://doi.org/10.25271/sjuoz.2021.9.1.783

\begin{abstract}
:
A nanodrop spectrophotometric method was developed and validated for determination of amlodipine besylate (AB) in bulk and tablet dosage form. The maximum absorption of amlodipine was shown at $357 \mathrm{~nm}$ using acetonitrile as a solvent. The developed method was found to be linear $\left(\mathrm{R}^{2}=0.9990\right)$ within the concentration range of $210 \mu \mathrm{g} / \mathrm{mL}$. The precision study showed acceptable values of RSD\% (less than 1\%). LOD and LOQ values were found to be 0.34 and $1.14 \mu \mathrm{g} / \mathrm{mL}$, respectively. Accuracy study showed good recovery $99 \%$ Awalodipine and $98.88 \%$ Amloneer, in locally commercial tablets. The present method was applied successfully for stability indicating study of AB inAwalodipine and Amloneer products manufacturedin (Erbil and sulaymaniyah, respectively)/ Kurdistan of Iraq. The stability-indicating study was investigated under acidic, basic, o xidative, photolytic, and thermal conditions. The results of both products showed that $\mathrm{AB}$ is unstable in acidic, alkaline, and oxidative conditions under heating at $60^{\circ} \mathrm{C}$ up to $5 \mathrm{hrsWhile}$ under photolytic and thermal conditions, the degradation percentageas less than $15 \%$ indicating to the stability of AB in both Awalodipine and Amloneer tablets according to International Conference on Harmonization (ICH) guideline of drugs. It can be concluded that the main factor that affects the degradation of AB is thepassage of time.
\end{abstract}

KEYWORDS: Amlodipine, Nanodrop spectrophotometer, Development, Validation, Stability Indicating.

\section{INTRODUCTION}

High pressure or hypertension is a chronic medical condition that raises high pressure in the arteries (Aram et al., 2003). Hypertension or high blood pressure is one of the mo st common vascular disorders causing a major risk factor for coronary heart disease, stroke, peripheral, cerebrovascular, and peripheral vascular disorders. For treatment of high blood pressure, anti -hypertensive medications are usually used which include different classes of drugs (Khatib et al., 2005).

Amlodipine besylate $(\mathrm{AB})$ is an antihypertensive drug and chemically described as 3-ethyl-5-methyl (4RS) -2-[(2aminoethoxy) methyl] -4-(2- chlorophenyl)-methyl-1ihydropyridine-3, 5-dicarboxylate benzenesulfonate with the chemical structure shown inFigure 1 (Abdoh et al., 2004). It belongs to a class of medications called dihydropyridine which is a calcium channel blocker acts by relaxing the smooth muscle in the arterial wall, and causes reducing blood pressure (Bernard et al., 2011). In reviewi ng the literature, many analytical methods were developed and validated for determination of $\mathrm{AB}$ alone or in combination with other drugs including spectrophotometry (Pradeep et al., 2009; Priyanka et al., 2012; Kumar et al., 2019; Kushwaha et al., 2019; Attimarad et al. , 2019), thin layer chromatography (TLC) ( Meyyanathan et al., 2005; Sharma et al., 2014; Mathew et al., 2014), high performance liquid chromatography (HPLC) Chitlange et al., 2008; (Jadhav et al., 2013; Rima et al., 2013; Mohamed et al.,2019) and, kinetic ( Hemmateenejadet al., 2009; Mahmoud et al., 2012).

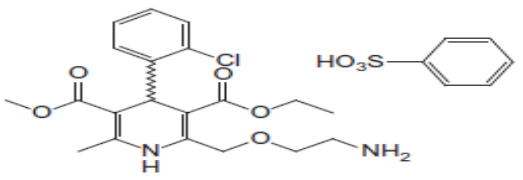

Figure 1. Chemical structure of Amlodipine besylate.

Stability indicating is an important part of the process of pharmaceutical product development. The purpose of stability indicating is to provide evidence on how the quality of the drug product varies with time under va rious environmental effects (Chatuevedi et al., 2004). Forced degradation study involves the possibility of degradation of drug $p$ roduct under extremely conditions such as acid, alkaline, oxidative, thermal, and light (Chakraborty et al. , 2018). Study the stability of drug allows selecting proper formulation and packaging for appropriate storage and shelf -life conditions, which are important for regulatory documents of developing any pharmaceutical product. The present study aims to develop and validate a new analytical method using nanodrop spectrophotometer for routine analysis and stability-indicating study of amlodipine besylate in pure form and pharmaceutical tablets.

\section{MATERIALS AND METHODS}

\subsection{Chemicals}

Pharmaceutically active ingredient ( $99 \%$ purity) of amlodipine besylate was purchased from Awa medical compny in Kurdistan of Iraq. Commercial tablets of Awalodipine $(100 \mathrm{mg})$ and Amloneer $(100 \mathrm{mg}$ ) from Awa and Pioneer companies in (Erbil and sulaymaniyah, respectively) Kurdistan of Iraq were procured from the local drug shops. Regents of hydrochloric acid and sodium hydroxide (Scharlau, Spain), hydrogen peroxide (Roth, Germany) were analytical grades . Acetonitrile, methanol, and water (Merck, Germany) were HPLC grade.

\footnotetext{
* Corresponding author

This is an open access under a CC BY -NC-SA 4.0 license (https://creativecommons.org/licenses/by -nc-sa/4.0/)
} 


\subsection{Instrumentation}

Spectrophotometric analysis was carried using nanodrop spectrophotometer (2000C Micro volume) from Thermo Scientific. UV lamp (UVC-215 TS 8W, 220-240v, 50/6 Hz) was used for photo degradation study. The analytical balance was $\operatorname{Voyager}^{(B)}$. The water bath shaker was Elmasonic P $(100 \mathrm{~W}, 80 \mathrm{KHz})$ and the oven was Lab Tech (LVO-2030).

\subsection{Preparation of stock and working solutions}

Weighed accurately $100 \mathrm{mg}$ of pure amlodipine besylate (AB) was dissolved in acetonitrile then transferred to $100 \mathrm{~mL}$ volumetric flask, and final volume made up to mark with acetonitrile to prepare $1000 \mu \mathrm{g} / \mathrm{mL}$ of stock standard solution. This stock standard solution was kept in a fridge and used to prepare different concentrations of working solutions.

\subsection{Method Optimization}

The maximal absorption wavelength $(\lambda \max )$ of the AB solution $50 \mu \mathrm{g} / \mathrm{mL}$ was determined using a nanodrop spectrophotometer within a wavelength range of 200-800 nm against acetonitrile as blank, $\lambda$ max was found to be $357 \mathrm{~nm}$. Preliminary solubility study of $\mathrm{AB}$ was also investigated testing different solvents namely water, methanol and acetonitrile.

\subsection{Method Validation}

According to the International Conference on Harmonization (ICH) guideline, the nanodrop spectrophotometric method was validated in terms of system, linearity, precision, LOD, LOQ, accuracy, specificity, and robustness.

\subsection{Forced degradation study}

Stability study of $\mathrm{AB}$ in pharmaceutical formulation was performed under Examine conditions including acidic (0.1N $\mathrm{HCl})$, alkaline $(0.1 \mathrm{~N} \mathrm{NaOH})$, oxidant $\left(5 \%(\mathrm{v} / \mathrm{v}) \mathrm{H}_{2} \mathrm{O}_{2}\right)$, thermal $\left(60{ }^{\circ} \mathrm{C}\right)$, and photolytic (sunlight, UV, and dark) at various periods. Two products of Awalodipine and Amloneer, were tested in this study.

2.6.1 Preparation of stock solution of formulation: Twenty tablets $(2.0 \mathrm{~g})$ from each commercial product, (each tablet of $100 \mathrm{mg}$ contains $5 \mathrm{mg}$ of $\mathrm{AB}$ ) were weighed accurately and finely powdered. Tablets powder equivalent to $100 \mathrm{mg}$ of $\mathrm{AB}$ was taken in a $100 \mathrm{~mL}$ beaker and $30 \mathrm{~mL}$ of acetonitrile was added to the beaker then sonicated for 15 minutes. The solution was filtered in $100 \mathrm{~mL}$ volumetric flask using Whatman filter paper $(0.45 \mu \mathrm{m})$ and then the volume was made up to the mark with acetonitrile to form a stock solution containing $1000 \mu \mathrm{g} / \mathrm{mL}$ of AB. From this stock solution of formulation, working solutions at different concentration were prepared.

2.6.2 Preparation of blank solution: To prepare blank solution, $12.5 \mathrm{~mL}$ of each reagent used for degradation (including $0.1 \mathrm{~N} \mathrm{HCl}, 0.1 \mathrm{~N} \mathrm{NaOH}$, and $5 \% \mathrm{H}_{2} \mathrm{O}_{2}$ ) was transferred to $25 \mathrm{~mL}$ volumetric flask and the volume was completed with acetonitrile and heated at $60^{\circ} \mathrm{C}$. From this solution, $2 \mathrm{~mL}$ of an aliquot taken in separate $10 \mathrm{~mL}$ volumetric flask at different time intervals and neutralized with proper reagent, and then the final volume was made up to mark with acetonitrile and the absorbance was measured at $357 \mathrm{~nm}$.
2.6.3 Acidic condition: $\mathrm{In} 25 \mathrm{~mL}$ volumetric flask, $12.5 \mathrm{~mL}$ from the stock solution $(100 \mu \mathrm{g} / \mathrm{mL})$ of drug was transferred and $12.5 \mathrm{~mL}$ of $0.1 \mathrm{~N}$ of $\mathrm{HCl}$ was added, and then heated to $60^{\circ} \mathrm{C}$. At the beginning $2 \mathrm{~mL}$ of this solution was taken at room temperature. Then, another $2 \mathrm{~mL}$ from this solution was transferred into separate volumetric flask $(10 \mathrm{~mL})$ at different times up to $5 \mathrm{hrs}$. After neutralizing with a suitable reagent the total volume was completed with acetonitrile to obtain $10 \mu \mathrm{g} / \mathrm{mL}$ of AB. The absorbance was measured against blank at $357 \mathrm{~nm}$.

2.6.4 Basic condition: The same procedure in section 2.6.3 was followed replacing $0.1 \mathrm{~N}$ of $\mathrm{HCl}$ with $0.1 \mathrm{~N}$ of $\mathrm{NaOH}$.

2.6.5 Oxidation condition: The same procedure in section 2.6.3 was followed replacing $0.1 \mathrm{~N}$ of $\mathrm{HCl}$ with $5 \%$ of $\mathrm{H}_{2} \mathrm{O}_{2}$.

2.6.6 Photo degradation: Three replicates of $12.5 \mathrm{~mL}$ from a stock solution $(100 \mu \mathrm{g} / \mathrm{mL})$ of drug were transferred into $25 \mathrm{~mL}$ volumetric flasks to prepare three solutions containing $50 \mu \mathrm{g} / \mathrm{mL}$ of $\mathrm{AB}$. These solutions were exposed to different circumstances including sunlight, UV, and dark up to 6 days. From each solution, $2 \mathrm{~mL}$ was transferred into $10 \mathrm{~mL}$ of volumetric flask after every 1 day, and the final volume was made up with acetonitrile to form solution containing $10 \mu \mathrm{g} / \mathrm{mL}$ of $\mathrm{AB}$. The absorbance was measured at $357 \mathrm{~nm}$ against acetonitrile as blank.

2.6.7 Thermal degradation: Accurate weight of $2.0 \mathrm{~g}(20$ tablets) of drug was taken and powdered by mortal and then exposed in an oven at $60{ }^{\circ} \mathrm{C}$ up to $6 \mathrm{hrs}$. From this powdered, 20 $\mathrm{mg}$ of exposed drug was dissolved in acetonitrile then transferred into $10 \mathrm{~mL}$ volumetric flask that was sonicated for 15 minutes and the final volume was made with acetonitrile to form a solution containing $10 \mu \mathrm{g} / \mathrm{mL}$ of $\mathrm{AB}$. The absorbance was measured (at $\lambda \max =357 \mathrm{~nm}$ ) against acetonitrile as blank.

\section{RESULT AND DISCUSSION}

\subsection{Method Optimization}

Developing and validating analytical method aims to confirm a suitable method for analysis a particular analyte with specific, accurate, and precise results. The main objective for that is to improve the conditions and parameters followed in the development and validation methods, therefore a wide variety of procedures need to be tested.

3.1.1 Scanning and determination of $\lambda_{\text {max }}$ : The spectrum of $\mathrm{AB}$ showed maximum absorption at $357 \mathrm{~nm}$ as shown in Figure 2. This wavelength was used later for all study measurements.

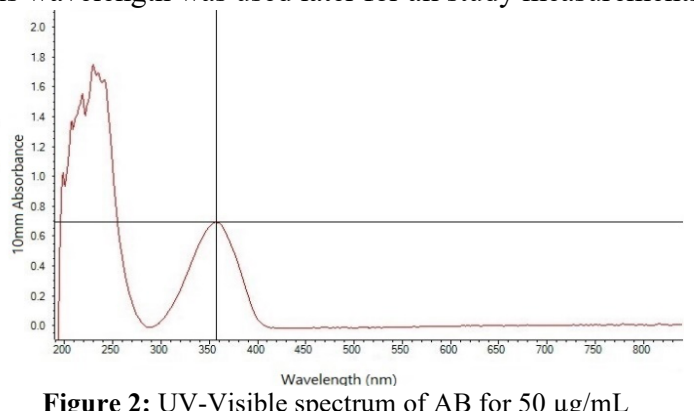

Figure 2: UV-Visible spectrum of $\mathrm{AB}$ for $50 \mu \mathrm{g} / \mathrm{mL}$

3.1.2 Type of solvent: The effect of the solvent was studied testing different solvents namely water, methanol and acetonitrile. $1 \mathrm{mg}$ of pure $\mathrm{AB}$ was weighed and solubility was checked in $10 \mathrm{~mL}$ solvent. The drug was found to be freely soluble in acetonitrile and methanol than water. Measuring the absorbance showed that using acetonitrile gave the highest absorbance $(0.180)$ at $357 \mathrm{~nm}$ than in water $(0.167)$ and, methanol (0.134). Therefore, acetonitrile was used as a solvent in this study. 


\subsection{Method Validation}

Method validation is process for the collection and evaluation of data to establish precise evidence that the analytical method is capable of producing quality products (Sekhar et al., 2020). The developed method was validated according to ICH guidelines for the linearity, precision, accuracy, specificity, robustness, LOD and LOQ.

3.2.1 Linearity: The linearity of the analytical method is the ability of the method to produce test results that are directly proportional to the analyte concentration in the sample (within a given range)(Prajakta et al., 2018). The linearity was investigated at concentration range of 2-10 $\mu \mathrm{g} / \mathrm{mL}$. The linear relationship expressed by the coefficient of determination $\left(\mathrm{R}^{2}\right)$ of the regression line which was found to be 0.9990 showing a good linearity. The ICH acceptance criteria of the linear regression is $\geq 0.9900$ (Ferenczi-Fodor et al., 2001).

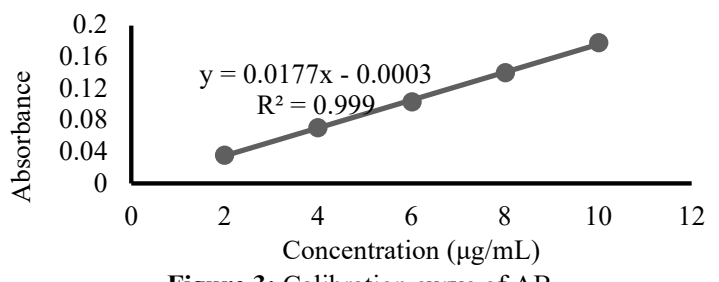

Figure 3: Calibration curve of $\mathrm{AB}$

3.2.2 Precision: The precision was evaluated by repeated injection, intra-day and inter-day study of $5 \mu \mathrm{g} / \mathrm{mL}$ of $\mathrm{AB}$ solution. Table 1 shows RSD\% values which are less than $1 \%$ indicating to good precision according to standard criteria of $\mathrm{ICH}$.

Table 1: Evaluation of precision study

\begin{tabular}{|l|l|}
\hline Type of precision & RSD $\%$ \\
\hline Repeatability $(\mathrm{n}=5)$ & 0.79 \\
\hline Intraday $(\mathrm{n}=3)$ & 0.79 \\
\hline Interday $(\mathrm{n}=3)$ & 0.70 \\
\hline
\end{tabular}

3.2.3 LOD and LOQ: Limit of detection (LOD) of an analytical technique is the lowest concentration that can be detected and distinguished from zero but may not always be calculated as an exact measure. Whereas, limit of quantification (LOQ) is the lowest concentration of the analyte in a sample that can be quantitatively determined with suitable precision and accuracy ( Prajakta et al., 2018). LOD and LOQ can be calculated from the following formulas:

$\mathrm{LOD}=3.3 * \sigma / \mathrm{S}$

$\mathrm{LOQ}=10 * \sigma / \mathrm{S}$

Where $\sigma=$ standard deviation of response, $\mathrm{S}=$ slope of the calibration curve, Table 2, shows LOD and LOQ values at minimum levels of amlodipine.

Table 2: LOD and LOQ values obtained from the calibration curve of concentrations $(2-10 \mu \mathrm{g} / \mathrm{ml})$ of $\mathrm{AB}$

\begin{tabular}{|l|l|}
\hline Parameter & Value \\
\hline Linearity Range $(\mu \mathrm{g} / \mathrm{mL})$ & $2-10$ \\
Regression equation & $\mathrm{y}=0.0177 \mathrm{x}-0.0003$ \\
\hline $\mathrm{R}^{2}$ & 0.9990 \\
\hline Slope & 0.0177 \\
\hline Intercept & -0.0003 \\
\hline $\mathrm{SD}$ & 0.002 \\
\hline $\mathrm{LOD} \mu \mathrm{g} / \mathrm{mL}$ & 0.34 \\
\hline $\mathrm{LOQ} \mu \mathrm{g} / \mathrm{mL}$ & 1.14 \\
\hline
\end{tabular}

3.2.4 Recovery: The validity and accuracy of the proposed method were assessed by recovery study testing three replicates sample at concentration of $10 \mu \mathrm{g} / \mathrm{mL}$ of each drug (Awalodipine and Amloneer). The recovery results were $99.00 \%$ for Awalodipine and $98.88 \%$ for Amloneer.

3.2.5 Specificity: Specificity is the ability to assess the analyte in the presence of components that may be expected to be present. Typically, these might include impurities and matrix ( Nagamani et al., 2013). The specificity of the present method was determined by adding (starch and magnesium) to the standard solution of $\mathrm{AB}$ and calculating the percent of the recovery for three replications which was found to be $99.8 \%$ with $\mathrm{RSD} \% 0.32$. The resultant showed that there was not interference from excipients in the analysis of standard $A B$.

3.2.6 Robustness: Robustness is measure of capability of method to remain unaffected by small variations in method parameters ( Koumudi et al., 2012). The effect of change in the wavelength from 355 to 359 , in the absorbance was studied. Standard solution of $\mathrm{AB}(5 \mu \mathrm{g} / \mathrm{mL})$ was prepared and analyzed at different wavelength. The RSD \% of absorbance measurement was found to be less than $1 \%$.

Validation of the present analytical method showed it is linear, precise, accurate, specify, and robustness with low values of LOD and LOQ. The present method met the standard criteria of $\mathrm{ICH}$ guidelines and can be used for analysis of amlodipine in quality control laboratories and stability indicating.

\subsection{Forced degradation study}

Forced degradation experiments provide awareness of potential degradation of the active ingredient under experimental conditions such as acid, alkaline, oxidative, thermal, and light. The present method were applied for stability-indicating study of amlodipine in two locally commercial products at various conditions as following:

3.3.1 Acid degradation: In stress degradation study under acidic condition, the two products of $\mathrm{AB}$ (Awalodipine and Amloneer) were exposed to $0.1 \mathrm{~N} \mathrm{HCl}$ at $60^{\circ} \mathrm{C}$ up to $5 \mathrm{hrs}$. Prior to heating it was found that $\mathrm{AB}$ in both products started to degrade at room temperature as shown in Table 3. At $60^{\circ} \mathrm{C}$ temperature the degradation of both products were increased with increasing the time from 1 to $5 \mathrm{hrs}$. It can be concluded that the longer the drugs were kept under acidic and heat conditions, the more degradation can occur.

Table 3: Acid hydrolysis effect on the amlodipine in Awalodipine and

\begin{tabular}{|c|c|c|c|c|}
\hline sample name & $\begin{array}{c}\text { Exposure } \\
\text { conditions }\end{array}$ & $\begin{array}{c}\text { Conc. } \\
\text { Given } \\
(\mu \mathrm{g} / \mathrm{mL})\end{array}$ & $\begin{array}{c}\text { Conc. } \\
\begin{array}{c}\text { Found } \\
(\mu \mathrm{g} / \mathrm{mL})\end{array}\end{array}$ & $\begin{array}{c}\text { Degradation } \\
\%\end{array}$ \\
\hline \multirow{5}{*}{ Awalodipine } & $\mathrm{RT}$ & 10 & 9.72 & 2.78 \\
\cline { 2 - 5 } & $1 \mathrm{~h} 60^{\circ} \mathrm{C}$ & 10 & 8.28 & 17.22 \\
\cline { 2 - 5 } & $2 \mathrm{~h} 60^{\circ} \mathrm{C}$ & 10 & 8.00 & 20.00 \\
\cline { 2 - 5 } & $3 \mathrm{~h} 60^{\circ} \mathrm{C}$ & 10 & 7.56 & 24.44 \\
\cline { 2 - 5 } & $4 \mathrm{~h} 60^{\circ} \mathrm{C}$ & 10 & 7.28 & 27.22 \\
\cline { 2 - 5 } & $5 \mathrm{~h} 60^{\circ} \mathrm{C}$ & 10 & 6.72 & 32.78 \\
\hline \multirow{5}{*}{ Amloneer } & $\mathrm{RT}$ & 10 & 7.78 & 22.22 \\
\cline { 2 - 5 } & $1 \mathrm{~h} 60^{\circ} \mathrm{C}$ & 10 & 7.44 & 25.56 \\
\cline { 2 - 5 } & $2 \mathrm{~h} 60^{\circ} \mathrm{C}$ & 10 & 7.11 & 28.89 \\
\cline { 2 - 5 } & $3 \mathrm{~h} 60^{\circ} \mathrm{C}$ & 10 & 6.56 & 34.44 \\
\cline { 2 - 5 } & $4 \mathrm{~h} 60^{\circ} \mathrm{C}$ & 10 & 6.44 & 35.56 \\
\cline { 2 - 5 } & $5 \mathrm{~h} 60^{\circ} \mathrm{C}$ & 10 & 5.56 & 44.44 \\
\hline
\end{tabular}


3.3.2 Alkaline degradation: In stress degradation study under alkaline condition, both products of $\mathrm{AB}$ (Awalodipine and Amloneer) were exposed to $0.1 \mathrm{~N} \mathrm{NaOH}$ up to $5 \mathrm{hrs}$. Preliminary, at room temperature both products were found to be unstable and lost small percentage from their actual amounts as shown in Table 4. However, when exposed to $60^{\circ} \mathrm{C}$ up to $5 \mathrm{hrs}$ the percentage of degradation was increased with the time. The results also showed that $\mathrm{AB}$ in Amloneer product has less degradation than the Awalodipine product in basic and heating conditions.

Table 4: Alkaline hydrolysis effect on the amlodipine in Awalodipine and Amloneer products.

\begin{tabular}{|c|c|c|c|c|}
\hline \multirow{4}{*}{$\begin{array}{c}\text { sample } \\
\text { name }\end{array}$} & $\begin{array}{c}\text { Exposure } \\
\text { conditions }\end{array}$ & $\begin{array}{c}\text { Conc. Given } \\
(\mu \mathrm{g} / \mathrm{mL})\end{array}$ & $\begin{array}{c}\text { Conc. Found } \\
(\mu \mathrm{g} / \mathrm{mL})\end{array}$ & $\begin{array}{c}\text { Degradation } \\
\%\end{array}$ \\
\hline \multirow{5}{*}{$\begin{array}{c}\text { Awalodipi } \\
\text { ne }\end{array}$} & $\mathrm{RT}$ & 10 & 9.56 & 4.44 \\
\cline { 2 - 5 } & $1 \mathrm{~h} 60^{\circ} \mathrm{C}$ & 10 & 6.67 & 33.33 \\
\cline { 2 - 5 } & $2 \mathrm{~h} 60^{\circ} \mathrm{C}$ & 10 & 6.44 & 35.56 \\
\cline { 2 - 5 } & $3 \mathrm{~h} 60^{\circ} \mathrm{C}$ & 10 & 5.94 & 40.56 \\
\cline { 2 - 5 } & $4 \mathrm{~h} 60^{\circ} \mathrm{C}$ & 10 & 5.72 & 42.78 \\
\cline { 2 - 5 } & $5 \mathrm{~h} 60^{\circ} \mathrm{C}$ & 10 & 5.61 & 43.89 \\
\hline \multirow{5}{*}{ Amloneer } & $\mathrm{RT}$ & 10 & 9.67 & 3.33 \\
\cline { 2 - 6 } & $1 \mathrm{~h} 60^{\circ} \mathrm{C}$ & 10 & 8.17 & 18.33 \\
\cline { 2 - 6 } & $2 \mathrm{~h} 60^{\circ} \mathrm{C}$ & 10 & 7.00 & 30.00 \\
\cline { 2 - 6 } & $3 \mathrm{~h} 60^{\circ} \mathrm{C}$ & 10 & 6.50 & 35.00 \\
\cline { 2 - 6 } & $4 \mathrm{~h} 60^{\circ} \mathrm{C}$ & 10 & 6.39 & 36.11 \\
\cline { 2 - 6 } & $5 \mathrm{~h} 60^{\circ} \mathrm{C}$ & 10 & 6.22 & 37.78 \\
\hline
\end{tabular}

3.3.1 Oxidation degradation: In this study, the results showed the highest degradation for $\mathrm{AB}$ under oxidative condition using $5 \% \mathrm{H}_{2} \mathrm{O}_{2}$. The $\mathrm{AB}$ in both products started degradation at room temperature particularly with Amloneer $(25 \%)$. After heating at $60{ }^{\circ} \mathrm{C}$, the percentage of degradation increased with time increasing from 1 to $5 \mathrm{hrs}$. Table 5 shows the results.
Table 5: Oxidative effect on the amlodipine in Awalodipine and Amloneer products.

\begin{tabular}{|c|c|c|c|c|}
\hline $\begin{array}{c}\text { sample } \\
\text { name }\end{array}$ & $\begin{array}{c}\text { Exposure } \\
\text { conditions }\end{array}$ & $\begin{array}{c}\text { Conc. Given } \\
(\mu \mathrm{g} / \mathrm{mL})\end{array}$ & $\begin{array}{c}\text { Conc. Found } \\
(\mu \mathrm{g} / \mathrm{mL})\end{array}$ & $\begin{array}{c}\text { Degradation } \\
\%\end{array}$ \\
\hline \multirow{4}{*}{$\begin{array}{c}\text { Awa } \\
\text { lodipine }\end{array}$} & $\mathrm{RT}$ & 10 & 9.17 & 8.33 \\
\cline { 2 - 5 } & $1 \mathrm{~h} 60^{\circ} \mathrm{C}$ & 10 & 7.33 & 26.67 \\
\cline { 2 - 5 } & $2 \mathrm{~h} 60^{\circ} \mathrm{C}$ & 10 & 6.33 & 36.67 \\
\cline { 2 - 5 } & $3 \mathrm{~h} 60^{\circ} \mathrm{C}$ & 10 & 3.17 & 68.33 \\
\cline { 2 - 5 } & $4 \mathrm{~h} 60^{\circ} \mathrm{C}$ & 10 & 1.22 & 87.78 \\
\cline { 2 - 5 } & $5 \mathrm{~h} 60^{\circ} \mathrm{C}$ & 10 & 0.28 & 97.22 \\
\hline \multirow{4}{*}{$\begin{array}{c}\text { Amlone } \\
\text { er }\end{array}$} & $\mathrm{RT}$ & 10 & 7.50 & 25.00 \\
\cline { 2 - 5 } & $1 \mathrm{~h} 60^{\circ} \mathrm{C}$ & 10 & 6.72 & 32.78 \\
\cline { 2 - 5 } & $2 \mathrm{~h} 60^{\circ} \mathrm{C}$ & 10 & 6.67 & 33.33 \\
\cline { 2 - 5 } & $3 \mathrm{~h} 60^{\circ} \mathrm{C}$ & 10 & 6.50 & 35.00 \\
\cline { 2 - 5 } & $4 \mathrm{~h} 60^{\circ} \mathrm{C}$ & 10 & 5.17 & 48.33 \\
\cline { 2 - 5 } & $5 \mathrm{~h} 60^{\circ} \mathrm{C}$ & 10 & 1.67 & 83.33 \\
\hline
\end{tabular}

3.3.2 Photolytic degradation: In stress degradation study under photolytic conditions, amlodipine (Awalodipine and Amloneer) were exposed to sun, UV and dark at different day intervals. Both the Awalodipine and Amloneer products show a little degradation (less than 15\%) up to 6 days and therefore the $\mathrm{AB}$ was found to be stable under photolytic conditions according to the ICH guideline that recommended below $15 \%$ is not measured as degradation because some of percent of this degradation is related to the drug formulation and preparation. Table 6 shows the results.

3.3.3 Thermal degradation: The thermal degradation was investigated exposing amlodipine (Awalodipine and Amloneer) at solid state to $60{ }^{\circ} \mathrm{C}$ for $6 \mathrm{hrs}$ in an oven. The loss percentages were found to be close $11.67 \%$ and $11.1 \%$ of both Awalodipine and Amloneer, respectively. These results indicated that $\mathrm{AB}$ remains stable in both products according to the $\mathrm{ICH}$ guideline.

Table 6: Photolytic effect on the amlodipine in Awalodipine products.

\begin{tabular}{|c|c|c|c|c|c|}
\hline sample name & Exposure conditions & time & Conc. Given $(\mu \mathrm{g} / \mathrm{mL})$ & Conc. Found $(\mu \mathrm{g} / \mathrm{mL})$ & Degradation $\%$ \\
\hline \multirow{18}{*}{ Awalodipine } & \multirow{6}{*}{1.} & 1 day & 10 & 9.89 & 1.11 \\
\hline & & 2 day & 10 & 9.83 & 1.67 \\
\hline & & 3 day & 10 & 9.28 & 7.22 \\
\hline & & 4 day & 10 & 9.22 & 7.78 \\
\hline & & 5 day & 10 & 8.78 & 12.22 \\
\hline & & 6 day & 10 & 8.61 & 13.89 \\
\hline & \multirow{6}{*}{ SUN } & 1 day & 10 & 9.89 & 1.11 \\
\hline & & 2 day & 10 & 9.56 & 4.44 \\
\hline & & 3 day & 10 & 9.39 & 6.11 \\
\hline & & 4 day & 10 & 8.89 & 11.11 \\
\hline & & 5 day & 10 & 7.94 & 13.33 \\
\hline & & 6 day & 10 & 7.72 & 13.89 \\
\hline & \multirow{6}{*}{ DARK } & 1 day & 10 & 9.89 & 1.11 \\
\hline & & 2 day & 10 & 9.83 & 1.67 \\
\hline & & 3 day & 10 & 9.56 & 4.44 \\
\hline & & 4 day & 10 & 9.33 & 6.67 \\
\hline & & 5 day & 10 & 9.22 & 7.78 \\
\hline & & 6 day & 10 & 8.89 & 11.11 \\
\hline \multirow{10}{*}{ Amloneer } & \multirow{6}{*}{ UV } & 1 day & 10 & 9.94 & 0.56 \\
\hline & & 2 day & 10 & 9.78 & 2.22 \\
\hline & & 3 day & 10 & 9.67 & 3.33 \\
\hline & & 4 day & 10 & 9.33 & 6.67 \\
\hline & & 5 day & 10 & 9.22 & 7.78 \\
\hline & & 6 day & 10 & 8.61 & 13.89 \\
\hline & \multirow{4}{*}{ SUN } & 1 day & 10 & 9.94 & 0.56 \\
\hline & & 2 day & 10 & 9.89 & 1.11 \\
\hline & & 3 day & 10 & 9.72 & 2.78 \\
\hline & & 4 day & 10 & 9.22 & 7.78 \\
\hline
\end{tabular}




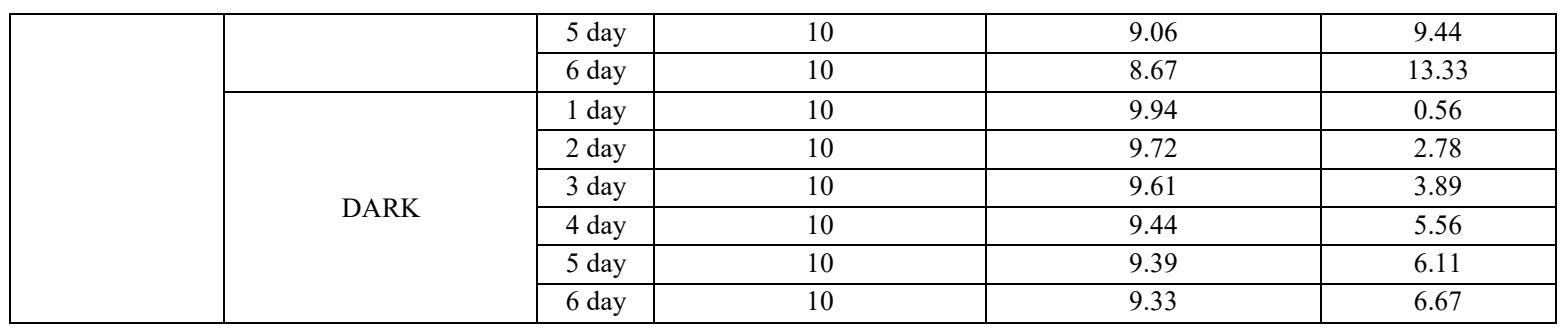

\section{CONCLUSION}

Nanodrop spectrophotometer method was developed and validated for determination of amlodipine in tablets dosage formulation. The develop method was found to be rapid, linear, precise, accurate, specified, sensitive, robustness' and, economic. The present method was applied successfully for forced degradation study of amlodipine of two products (Awalodipine and Amloneer) by exposing to extreme conditions including acidic, basic, oxidative, photolytic and thermal degradation. According to ICH guideline of drugs, the $\mathrm{AB}$ (Awalodipine and Amloneer) was found to be unstable in acidic, basic, and oxidative conditions under heating at $60^{\circ} \mathrm{C}$ showing high degradation percentage more than $15 \%$. The results showed highest degradation for $\mathrm{AB}$ under oxidative condition using $5 \% \mathrm{H}_{2} \mathrm{O}_{2}$ with both products. The main factor that affects the degradation of $\mathrm{AB}$ is the passage of time. The percentage of degradation increases through different stress factors, but the effect of time remains stronger.

\section{ACKNOWLEDGEMENTS}

The author would like to thank Mr. Samie yaseen sharaf and Shekhan technical college of health for his help during this study

\section{REFERENCE}

Abdoh, A., Al-Omari, M. M., Badwan, A. A., \& Jaber, A. M. Y. (2004). Amlodipine Besylate-Excipients Interaction in Solid Dosage Form, Pharmaceutical Development and Technology, 9(1), pp. 15-24. Doi: 10.1081/PDT-120027414.

Aram, V., George, L., Henry, R., William, C., Lee, A., Joseph, L., Daniel, W., Barry, J., Suzanne, O., Jackson, T., \& Edward J. (2003). Seventh report of the Joint National Committee on Prevention, Detection, Evaluation, and Treatment of High Blood Pressure, Hypertension, 42(6), pp. 1206-1252. Doi: 10.1161/01.HYP.0000107251.49515.c2.

Attimarad M., Venugopla K., Bandar E., Nagaraja S., And Anroop Ba.(2019) Development of UV Spectrophotometric Procedures for Determination of Amlodipine and Celecoxib in Formulation: Use of Scaling Factor to Improve the Sensitivity, Journal of Spectroscopy, 2019. Doi: 10.1155/2019/8202160.

Bernard, S., Mathew, M., \& Senthilkumar, K. L. (2011) Spectrophotometric method of estimation of Amlodipine besylate using hydrotropic solubilization, Journal of Applied Pharmaceutical Science, 1(9), pp. 177-180.

Chakraborty, S., Sharmin S., Rony S., Ahmad, S., \& Sohrab Md. (2018). Stability-indicating UV/vis spectrophotometric method for diazepam, development and validation, Indian Journal of Pharmaceutical Sciences, 80(2), pp. 366-373. Doi: 10.4172/pharmaceutical-sciences.1000366.

Chatuevedi, k., \& Chaturved, S. (2004) stability indicating assay method for Amlodipine tablets.

Chitlange, S., Imran, M., \& Sakarkar, D. (2008). RP-HPLC method for simultaneous estimation of Amlodipine and metoprolol in tablet formulation, Asian Journal of Pharmaceutics, 018(December), pp. 232-234.

Ferenczi-Fodor, K. Et al. (2001) 'Validation and quality assurance of planar chromatographic procedures in pharmaceutical analysis', Journal of AOAC International, 84(4), pp. 12651276. Doi: 10.1093/jaoac/84.4.1265.

Hemmateenejad, B. (2009). A Kinetic Spectrophotometric Method for Determination of Amlodipine and Nifedipine in pharmaceutical preparations, 25(2), pp. 31-38.
Khatib O., \& Mohamed G. (2005). clinical duidlines for the managment of hypertension.

Koumudi Annamaneni. (2012). method development and validation of simultaneous estimation of telmisartan and hydrochlorothiazide in pharmaceutical dosage forms by RPHPLC.

Kumar, M., Mohit J., \& Shailendra B. (2019). Simultaneous Estimation of Amlodipine Besylate and Ramipril in Tablets Dosage Form by UV Spectrophotometric Method, Journal of Pharmaceutical Sciencees and Research, 11(2), pp. 667-670.

Kushwaha, D., Sunil D., Sarita K., \& Hemant K.(2019). Novel UV Spectrophotometer Methods for Quantitative Estimation of Concensi (Amlodipine 10mg and Celecoxib 200mg) Using Hydrotropic Solubilizing Agents, Journal of Drug Delivery and Therapeutics, 9(4-A), pp. 651-655.

Mahmoud, A. M., Abdel-Wadood, H. M. \& Mohamed, N. A. (2012) Kinetic spectrophotometric method for determination of mlodipine besylate in its pharmaceutical tablets, Journal of Pharmaceutical Analysis. Elsevier, 2(5), pp. 334-341. Doi: 10.1016/j.jpha.2012.03.002.

Mathew, M., Sheyni, B., Senthil k., \& Girija A. (2014). development and validation of a HPTLC method for the simultaneous estimation of Atorvastatin calcium and Amlodipine besylate as the bulk drugs and in the tablet dosage form, Asian journal of pharmaceutical and Health Sciences, pp. 986-991.

Meyyanathan, S. N., \& Suresh, B. (2005). HPTLC method for the simultaneous determination of amlodipine and benazepril in their formulations, Journal of Chromatographic Science, 43(2), pp. 73-75. Doi: 10.1093/chromsci/43.2.73.

Mohamed, A. M. (2019). Simultaneous Determination of Amlodipine Besylate, Valsartan, and Its Related Substances in Their FilmCoated Tablets Dosage form by RP-HPLC Method, Advanced Journal of Chemistry-Section A, 2(4), pp. 337-346. Doi: 10.33945/sami/ajca.2019.4.7.

Nagamani, P., Manjunath, SY., Hemant Kumar, T. (2020). Development and validation of RP-HPLC method for estimation of amlodipine besylate and losartan potassium in multidrug marketed formulation, International Journal of Pharmacy and Technology, 5(1), pp. 5188-5198.

Prajakta, G., \& Ravindra, B. Saudagar. (2018). Review on analytical method development and validation by RP-HPLC.

Pradeep, M., Kamal, S., \& Alka, G. (2009). Spectrophotometric methods for simultaneous estimation of nebivolol hydrochloride and amlodipine besylate in tablets, International Journal of chemtech Research, 1(4), pp. 991995.

Priyanka, R., Sachin, U., \& Burade KB. (2009). Simultaneous UV Spectrophotometric methods for estimation of losartan potassium and amlodipine besylate in tablet dosage form, Research Journal of Pharmaceutical, Biological and Chemical Sciences, 3(3), pp. 397-404.

Rima, N. Shah., Deesha, B. Gandhi., \& Mehul M. Patel. (2013). Simultaneous estimation and forced degradation studies of amlodipine besylate and indapamide in tablet dosage form by RP-HPLC method, Der Pharma Chemica, 5(6), pp. 347-352.

Sekhar, K., Abbas, S., Chandra, M., Hamana, N., Kalyan, P., Rajesh, J., \& Varun, B. (2020). Validation methods of amlodipine drug with comparative study of standard and sample by using UV- spectroscopy, 18, pp. 100-104.

Sharma, M., Kothari, C., Sherikar, O., \& Mehta, P. (2014). Concurrent estimation of amlodipine besylate, hydrochlorothiazide and valsartan by RP-HPLC, HPTLC and UV-spectrophotometry, Journal of Chromatographic Science, 52(1), pp. 27-35. Doi: 10.1093/chromsci/bms200.

Topa, K., Pankaj, S., Paras, M. \& Tej, P. (2011). Nanodrop spectrophotometric method development and validation for estimation of ranolazine in their bulk, international journal pharmaceutical science researcher, 2(4), pp. 985-998. 